\title{
Physicochemical Characterization of Pulverized Phyllite Rock for Geopolymer Resin Synthesis
}

\author{
Lis Guimaraes de Azeredo Melo ${ }^{a}$, Rachel Andrade Pereira ${ }^{b}$, Eliane Fernandes Côrtes Pires',
}

Fathi Aref Ibrahim Darwish ${ }^{c}$, Felipe José da Silva ${ }^{a, b *}$

${ }^{a}$ Mechanical and Materials Engineering Section, Instituto Militar de Engenharia, Rio de Janeiro, RJ, Brazil

${ }^{b}$ Technical Course in Industrial Mechanics, Instituto Federal do Rio de Janeiro, Paracambi, RJ, Brazil

${ }^{c}$ Department of Civil Engineering, Universidade Federal Fluminense, Niterói, RJ, Brazil

Received: December 11, 2016; Revised: June 04, 2017; Accepted: June 08, 2017

\begin{abstract}
Geopolymeric materials have some unique properties such as early-high compressive strength, durability, resistance to acids and sulfates, ability to immobilize toxic and radioactive compounds, low porosity and high temperature resistance. These materials are strategic for sustainable development and are a suitable alternative to Portland cement. The use of phyllite as a geopolymer precursor is encouraged by its abundance, low cost, and the fact that it is already applied in ceramic industries as a kaolin substitute. The objective of this paper is the physicochemical characterization of geopolymeric resin using two pulverized phyllite rocks as precursors with STEM, XRD and XRF techniques. It was found that both phyllite rocks studied have a high quartz content of approximately $50 \%$ (weight), which have a "filler" function in the microstructure of the resin helping stabilize residual tensions after curing. Kaolinite and muscovite minerals are present in up to $40 \%$ (weight) and are responsible for the high compressive strength of the geopolymer resins.
\end{abstract}

Keywords: Phyllite, geopolymer resin, physicochemical characterization

\section{Introduction}

The mineral kaolin has been used for decades as the starting raw material for fabrication of mineral polymers or geopolymers with two and three-dimensional structures based on the functional unit of Si-O-Al. Since it is pure clay, its commercial value and local availability vary depending on the distance to the deposits or the distribution network.

Features such as whiteness, particle size or granulometry, aluminum and impurity content of kaolin are definite markers of the quality and employability in the synthesis of geopolymers. For example, trace content in the order of $\mathrm{ppm}$ of certain elements such as $\mathrm{Fe}$ and $\mathrm{Mg}$ can greatly affect the chemical stability of the polymeric chains, resulting in partial depolymerization, shrinkage and multiple cracking of the microstructure ${ }^{1}$.

Davidovits ${ }^{2}$ insists on addressing the difference between the geopolymer and the alkali-activated matrices. The former consists of a branched long chain polymer in 2D or crosslinked chains in 3D. NMR data for poly(sialate-siloxo) show that its main functional unit is $\mathrm{SiQ}_{4}-2 \mathrm{Al}$. This means that there is full saturation of silicon tetrahedra with 1:1 combination with aluminum, which has a four-fold coordination with oxygen atoms.

The condensation degree of the tetrahedral sialate in alkali-activated matrices is low resulting in the formation of

\footnotetext{
* e-mail: lismellow@gmail.com
}

dimers, trimers and tetramers. This could explain the lower mechanical properties and durability compared to polymerized matrices ${ }^{2}$. Therefore, the inferior performance has led to low research interest in the exploration alkali-activated matrices.

Geopolymers are poly-oxide-alumino-silicates obtained from the dissolution and polymerization of oxide-aluminosilicates in a highly alkaline aqueous environment. In order to be used in the geopolymerization, the oxide-aluminosilicate must present the aluminum cations in 4-fold coordination, occupying a tetrahedral position relative to the oxygen. Some examples of minerals that after calcination meet this basic requirement are tosudite, kaolinite, halloysite, amesite and chamosite $^{2,3,4}$. Aluminum is responsible for the cross-linking between the polymeric chains, which results in the configuration of the 3-D network of the geopolymer. However, reactivity depends not only on the chemical environment of Al, but also on the specific surface area of the powder (fineness) as well as the impurity content. Examples of impurity sources are $\mathrm{Fe}_{2} \mathrm{O}_{3}, \mathrm{TiO}_{2}$ and $\mathrm{SiO}_{2}$, which occur commonly in the form of ilmenite, rutile, anatase and quartz in the secondary kaolins ${ }^{3}$.

Metakaolin (calcined kaolin), an oxide-aluminosilicate, is the most used geopolymer precursor followed by fly ash (FA). Metakaolinite, present in metakaolin (MK), is the main source of aluminum in the geopolymer. The geopolymerization occurs due to the destruction and recombination of the aluminosilicate chains of the disorganized kaolinite 
(metakaolinite) from the action of $\mathrm{OH}^{-}$ions and alkalis, specifically in the aluminum-containing sites ${ }^{5}$. Therefore, any impediment to this reaction, such as the entrapment or insufficiency of ions or the substitution by impurity atoms in the original kaolinite structure, can modify the kinetics of the geopolymerization and even hinder obtaining the necessary structural properties in the geopolymer ${ }^{5}$.

In the Brazilian Civil Construction market, there has been a recent increase in the supply of the phyllite ore, integrating ready-mixed sand mortars and additives for use in coating mortars and laying of red ceramic masonry. Phyllite is composed mainly of $\mathrm{Al}$ and $\mathrm{Si}$, and is an easily pulverized rock providing ultrafine powder. Its essential components are small-sized grain phyllosilicates, such as finely divided mica-muscovite, or sericite, kaolinite, and quartz 6 . The main constituent of kaolin, kaolinite, is found in phyllite and highlights its potential as a precursor for geopolymeric matrices. It is known that phyllite is a material of great geological abundance in Brazil, of low cost and is already commonly applied in the ceramic industries as a partial substitute of kaolin. In addition to mortars, it is also used in: sanitary stoneware, animal feed, pigment and binder, special concretes, and waterproof materials, due to its low permeability ${ }^{7,8}$.

This paper presents the physical and microstructural characterization of two phyllite varieties and their calcined products used as geopolymer resin precursors in order to evaluate their potential for kaolin replacement.

\section{Materials and Methods}

Two varieties of phyllite, white and cream, supplied by Mineração Itapeva/SP and one kaolin from the deposits located in the region of Seridó Potiguar (RN/Brazil) were used. These geopolymer precursors and resins were characterized physically and chemically, as received, through X-ray Diffraction (XRD), Scanning Transmission Electron Microscopy (STEM) and X-ray fluorescence (XRF - Philips, PW - 2400, $3 \mathrm{~kW}$ rhodium source). A XRD Panalytical $\mathrm{X}$ 'Pert Pro model was used throughout this work. The copper tube had $\mathrm{K} \alpha \lambda=1,54 \AA$ and was operated at $40 \mathrm{kV}$ with a $40 \mathrm{~mA}$ current. The phase idenfication was done using PDF-02 Powder Diffraction Files (International Center for Diffraction Data - ICDD, 2003) from the X'Pert High Score Panalytical software. The STEM used was a JEOL model EM-2100F operated at $200 \mathrm{kV}$. STEM images and electron diffractograms were also taken with this instrument.

To obtain metakaolin, kaolin was calcined in a muffle furnace at $850^{\circ} \mathrm{C}$ for 2 hours, as recommended in previous studies by Barbosa et al. ${ }^{9}$. The phyllites were calcined in a muffle furnace at $850^{\circ} \mathrm{C}$, but at three different times, 2,4 and $6 \mathrm{~h}$, to verify the time necessary to ensure the transformation to the amorphous state of its minerals. A standard formulation for sodium, potassium and calcium polysialate-siloxo, $\mathrm{Na}, \mathrm{K}$,
Ca-PSS, whose molar ratios of reactant oxides is shown in Table 1 was used for preparation of the resin. Replacement levels of metakaolin with phyllite were 25, 50,75 and $100 \%$ in volume. The Standard Geopolymer (SG) was made with $100 \%$ metakaolin as the solid source of Al-Si. White phyllite geopolymer (WPG) with $75 \%$ white phyllite (WP) and $25 \%$ metakaolin was denoted as WPG-75. Cream phyllite geopolymer (CPG) with $50 \%$ of cream phyllite $(\mathrm{CP})$ and $50 \%$ of metakaolin was denoted as CPG-50, and so on. Commercially available sodium silicate $\left(\mathrm{Na}_{2} \mathrm{SiO}_{3} \mathrm{nH}_{2} \mathrm{O}\right)$ supplied by Una-Prosil S.A./RJ, using a $\mathrm{SiO}_{2} / \mathrm{Na}_{2} \mathrm{O}$ weight ratio of 2.36 and $52.1 \% \mathrm{H}_{2} \mathrm{O}$, was used as a complementary source of $\mathrm{SiO}_{2}$. To ensure an alkaline $\mathrm{pH}$ in geopolymerization potassium hydroxide $(\mathrm{KOH})$ commercial grade, manufactured by Panamericana S.A./RJ, was used. For the purpose of evaluating the mechanical properties of the hardened pastes, $25 \mathrm{~mm}$ diameter and $50 \mathrm{~mm}$ high specimens were tested in according to the requirements of ASTM D 695M:91. The water/dry binder ratio was 0.316 (weight) for all pastes and no aggregate particles were necessary to improve consistency or mechanical stabilizing. The same conditions for testing and drying were used regardless if pastes were not completely dried (i.e. $100 \%$ phyllite contained geopolymers). The specimens were cured at $80^{\circ} \mathrm{C}$ for 4 hours in an oven. The molds were made of polyethylene and during curing their tops were covered with PVC film and capped with a screw cap, as recommended by Barbosa et $\mathrm{al}^{9}$ and Zuhua et al..$^{10}$.

Table 1. Molar ratios of the synthesized geopolymers, where $\mathrm{M}=\mathrm{Na}$ and $\mathrm{K}$.

\begin{tabular}{cccc}
\hline Matrix & $\begin{array}{c}\mathrm{SiO}_{2} \\
\mathrm{Al}_{2} \mathrm{O}_{3}\end{array}$ & $\begin{array}{c}\mathrm{M}_{2} \mathrm{O} \\
\mathrm{CaO}\end{array}$ & $\begin{array}{c}\left(\mathrm{M}_{2} \mathrm{O}+\mathrm{CaO}\right) \\
\mathrm{Al}_{2} \mathrm{O}_{3}\end{array}$ \\
\hline SG & 3.65 & 1.20 & 1.62 \\
WPG-25 & 4.13 & 1.24 & 1.91 \\
WPG-50 & 4.79 & 1.29 & 2.32 \\
WPG-75 & 5.79 & 1.33 & 2.93 \\
WPG-100 & 7.47 & 1.38 & 3.95 \\
CPG-25 & 4.09 & 1.23 & 1.89 \\
CPG-50 & 4.70 & 1.26 & 2.26 \\
CPG-75 & 5.60 & 1.30 & 2.81 \\
CPG-100 & 7.04 & 1.35 & 3.71 \\
\hline
\end{tabular}

After compression rupture, samples were collected between the fragments, manually macerated in mortar and pestle of 6.0" agate stone, micronized in an automatic mill, and then submitted to XRD and TEM analysis.

\section{Results and Discussion}

The chemical composition of metakaolin and phyllites obtained from XRF is shown in Table 2. The higher Si/Al ratio indicates that kaolinite is not the main component of either phyllite. 
Table 2. Chemical composition of solid and Si source materials for the geopolymer resins obtained from XRF.

\begin{tabular}{cccc}
\hline \multirow{2}{*}{ Oxides } & \multicolumn{3}{c}{ Mass composition (\%) } \\
\cline { 2 - 4 } & $\mathrm{MK}$ & $\mathrm{CP}$ & $\mathrm{WP}$ \\
\hline $\mathrm{SiO}_{2}$ & 50.6 & 68.84 & 72.63 \\
$\mathrm{Al}_{2} \mathrm{O}_{3}$ & 41.0 & 15.72 & 14.98 \\
$\mathrm{Na}_{2} \mathrm{O}$ & 1.10 & 0.02 & 0.02 \\
$\mathrm{CaO}$ & 0.72 & 0.02 & 0.02 \\
$\mathrm{~K}_{2} \mathrm{O}$ & 0.09 & 4.35 & 5.07 \\
$\mathrm{Fe}_{2} \mathrm{O}_{3}$ & 0.62 & 4.81 & 1.37 \\
$\mathrm{MgO}$ & 0.34 & 1.52 & 1.83 \\
$\mathrm{TiO}_{2}$ & 0.14 & 0.91 & 0.61 \\
Others & 5.39 & 0.04 & 0.04 \\
L.O.I. & 2.03 & 3.95 & 3.00 \\
\hline
\end{tabular}

Figure 1 shows the X-ray diffractograms of kaolin (a) as received and (b) after calcination at $850^{\circ} \mathrm{C} / 2 \mathrm{~h}$, or metakaolin. As can be seen, all peaks relative to the kaolinite mineral disappeared after calcination, showing that the dehydroxylation was complete.

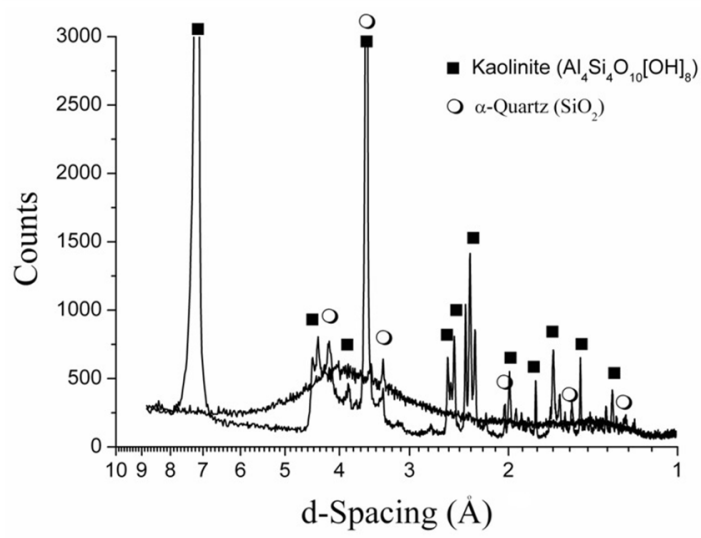

Figure 1. XRD of the kaolin before (well-defined peaks) and after calcination (broad spectrum) at $850^{\circ} \mathrm{C} / 2 \mathrm{~h}$, showing the suppression of the peaks attributed to the mineral kaolinite.
Figure 2 shows the X-ray diffractograms of (a) white (WP) and (b) cream phyllite (CP) as received and their 2 , 4 and $6 \mathrm{~h}$ of calcination products. Most of the kaolinite related peaks disappear for the calcined products. The various degrees of dehydroxylation of muscovite $2 M 1$ were attributed to structural and chemical rearrangements that caused expansion of the tetrahedral and octahedral sheets. This caused displacement of the diffraction peaks to lower angles and an inversion of the relationship between the intensities of the $2 M 1$ muscovite peaks after calcination at $850^{\circ} \mathrm{C}$. Goethite was transformed into hematite in the $\mathrm{CP}$ calcinated products. Increasing the calcination time did not induce significant microstructural modifications. Thus, the calcination of the phyllites at $850^{\circ} \mathrm{C} / 2 \mathrm{~h}$ was assumed to be sufficient to generate the geopolymer precursor.

The presence of calcium-rich and lamellar particles of metakaolinite (Figure 3a,b) were found in the $6 \mathrm{~h}$ calcined white phyllite. Tubular particles, which are a characteristic morphology of the mineral halloysite (Figure 3c) were observed in the metakaolin. Tailby ${ }^{11}$ investigated calcined kaolinite and halloysite geopolymers. Under heating, halloysite loses its crystalline structure, and becomes similar to metakaolin. It was verified that both presented the same reactivity in the geopolymerization. Thus, it was not necessary to identify which of the two polymorphic phases is present in metakaolin.

The different chemical and mineralogical compositions of the calcined phyllites suggest different reactivities of these materials in the geopolymer reaction. A mineralogical quantification between the white and cream phyllites was determined by the Rietveld method, as shown in Table 3 . The content of quartz reaches the $50 \%$ range in both phyllites. Rutile $\left(\mathrm{TiO}_{2}\right)$ and goethite $(\mathrm{FeO}[\mathrm{OH}])$, besides kaolinite, occur in a higher content in $\mathrm{CP}(8 \%)$.

The mechanical behavior of the geopolymer resins made with different concentrations of both phyllites were investigated and compared with the SG considered the control resin.

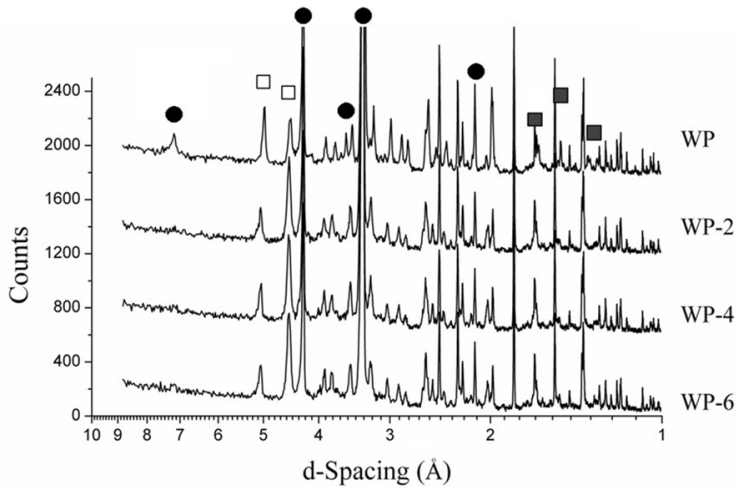

(a)

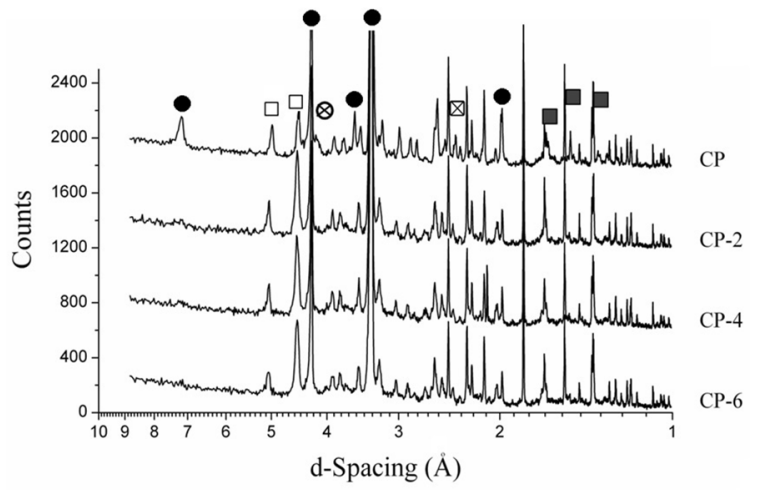

(b)

Figure 2. Comparative X-ray diffractograms of (a) white phyllite (WP) (b) cream phyllite (CP); and the calcination products at $850 \mathrm{oC}$ for 2, 4 and $6 \mathrm{~h}$, where $(\bullet)$ are the main kaolinite peaks; ( $\square$ ) shows partial dehydroxylation of muscovite $2 M_{i} ;(\boldsymbol{\bullet})$ shows the long-range disorder of muscovite and $(\otimes)$ shows goethite transformed into hematite $(区)$. The other peaks shown are due to quartz. 


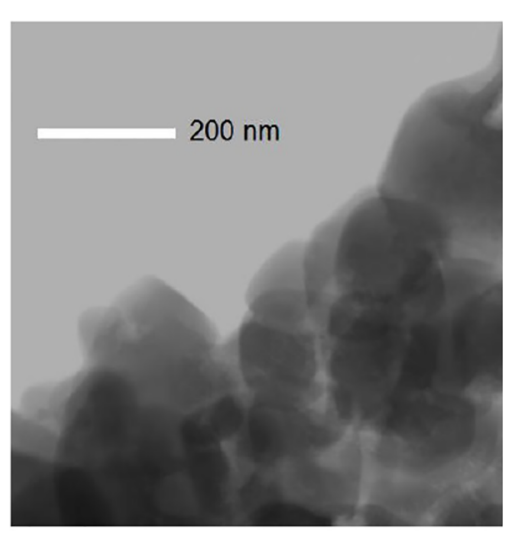

(a)

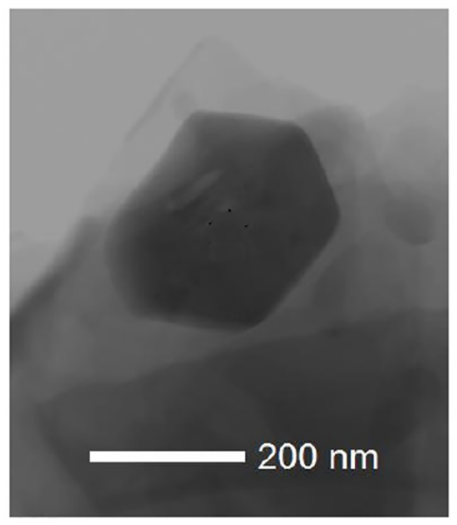

(b)

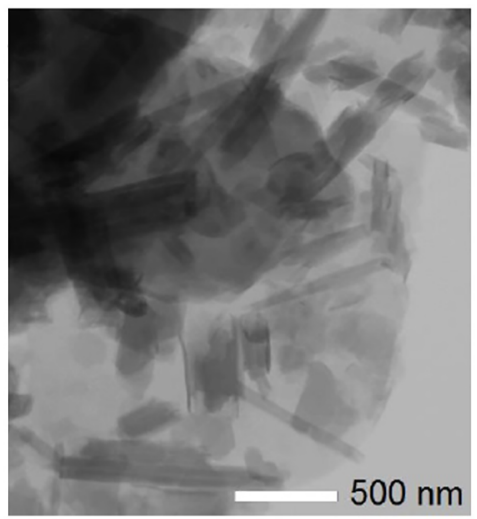

(c)

Figure 3. STEM Bright field images of $6 \mathrm{~h}$ calcined white phyllite with (a) agglomerates of calcium-rich particles (Energy Dispersive X-ray Spectroscopy results not shown) and (b) a particle with pseudo-hexagonal morphology characteristic of kaolinite. The Metakaolin had (c) tubular particles related either to the mineral halloysite or tubular kaolinite.

Table 3. Mineralogical composition of phyllites by the Rietveld Method.

\begin{tabular}{ccc}
\hline \multirow{2}{*}{ Mineral } & \multicolumn{2}{c}{ Content (\%) } \\
\cline { 2 - 3 } & WP & CP \\
\hline Quartz & 50.8 & 49.4 \\
Muscovite $1 M$ & 6.1 & 6.8 \\
Microcline & 2.0 & 1.2 \\
Muscovite $2 M_{l}$ & 37.4 & 31.2 \\
Kaolinite & 3.7 & 8.0 \\
Rutile & - & 1.0 \\
Goethite & - & 2.4 \\
TOTAL & 100.0 & 100.0 \\
\hline
\end{tabular}

Figure 4 shows the compressive strength of all the resins. The SG resin had a compressive strength of $20.5 \pm 5.3 \mathrm{MPa}$ and is shown as the $0 \% \mathrm{vol}$ of each phyllite in both graphs. The substitution of $25 \%$ (volume) of metacaulin with WP (non-calcined as well as the 2, 4 and $6 \mathrm{~h}$ calcinated products) increased the performance up to $34.2 \pm 4.5 \mathrm{MPa}$ for the WPG-6 (Figure 4a).

In the case of the CP, the substitution of up to $50 \%$ in vol resulted in geopolymer resins stronger than the control (SG), independent of the calcination time, and including the non-calcined CP. The compressive strengths were on average $35 \%$ higher $(27.6 \mathrm{MPa})$ compared to the white phyllite. The higher kaolinite content can explain the overall superior performance of the CP in comparison to the WP geopolymer pastes despite the presence of more impurities (higher $\mathrm{Fe}_{2} \mathrm{O}_{3}$ and $\mathrm{TiO}_{2}$ content in the form of goethite and rutile). Previous studies indicate that iron does interfere in the strength development of geopolymer ${ }^{13,14}$. However, it is more likely that other factors such as particle size and the mineralogical form of the iron play a more critical role in their reactivity ${ }^{13,14}$.

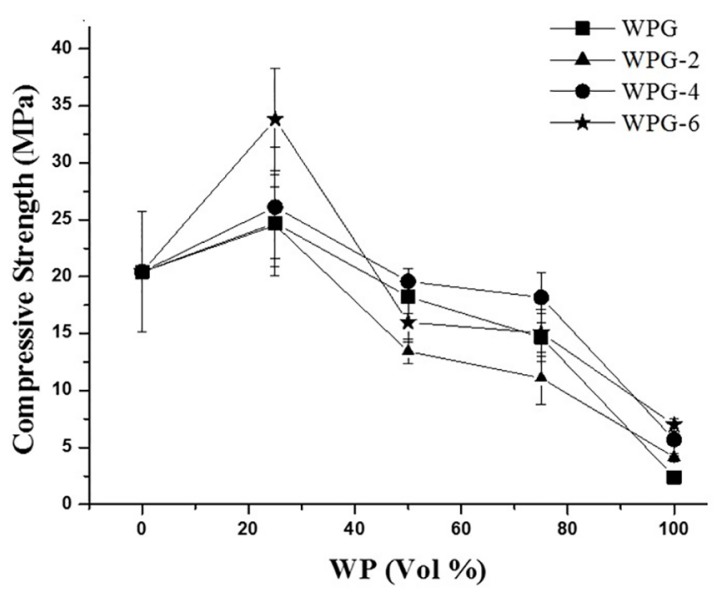

(a)

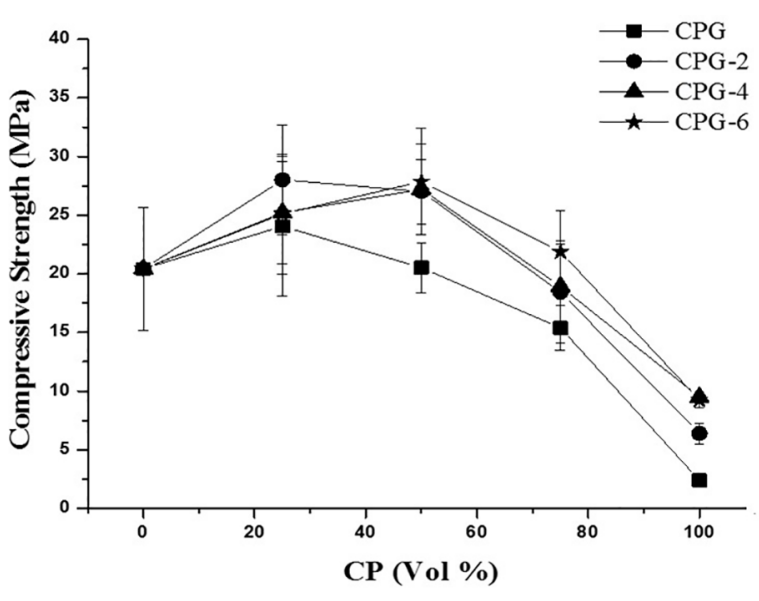

(b)

Figure 4. Compressive strength of geopolymeric resins according to metakaolin replacement content of (a) white phyllite; (b) cream phyllite; calcined for 2,4 or $6 \mathrm{~h}$ at $850^{\circ} \mathrm{C}$. 
When viewing the geopolymers synthesized with $75 \%$ of CP, only the use of the calcined for $6 \mathrm{~h}$ (CP-6) resulted in a compressive strength higher than that of SG (Figure $4 \mathrm{~b}$ ). In order to obtain the same compressive strength as the reference resin, SG, CPG-6 is capable of promoting the replacement of metakaolin by more than $80 \%$ by volume.

Both non-calcined phyllite geopolymers (WPG and $\mathrm{CPG}$ ) perform better than SG with $25 \%$ vol substitution. This is probably due to the presence of quartz which improves the strength of the geopolymer through the filler effect as a mechanical stabilizer ${ }^{12}$.

For the total substitution of metakaolin, the compressive strengths were, on average, $60 \%$ lower than the SG, for both phyllite types. This can be due to the excess of cations and insufficient $\mathrm{Al}$ available for reaction (see Table 1).

The presence of crystalline nanoparticles under two distinct gel phase morphologies was observed at nanometer scale in the SG (Figure 5). The largest of these, of equiaxial dimensions ranging from 50 to $400 \mathrm{~nm}$, occur separately. The others, of sizes up to $10 \mathrm{~nm}$, occur forming agglomerates (Figure 5a). Since these nanoparticles are partially crystalline (Figure 5b) they may be both remnants of the minerals present in the precursors that were dispersed and entrapped in the Al-Si gel phase, or nucleated zeolite crystals grown from the gel phase. The diffraction pattern as shown in Figure 5b was observed for all geopolymers and did not depend on the initial mineral phases present.

The result of the electron diffraction is complemented by XRD analysis (Figures 6,7a and 7b), which showed, for example, calcite formation on SG resin. The only mineralogical phases detected in the phyllite geopolymers were muscovite

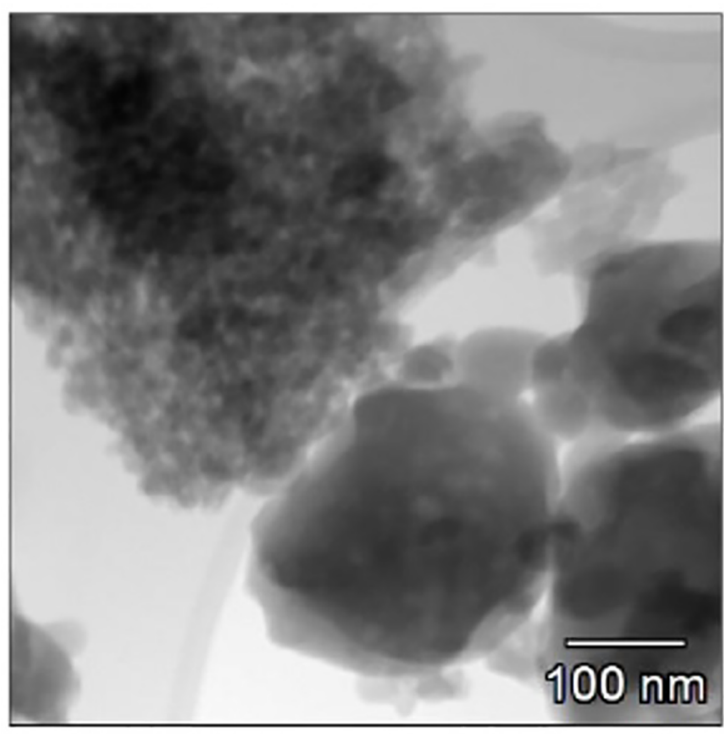

(a)

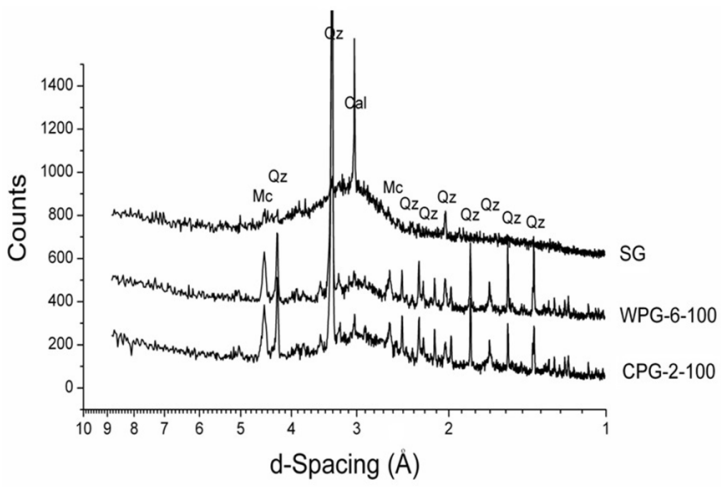

Figure 6. XRD comparing the SG resin with the WPG-6-100 and CPG-2-100 resins. Muscovite (Mc), quartz (Qz) and calcite (Cal) are indicated.

and quartz. The diffuse halo formation in the diffraction figure and the absence of the reflections attributed to the dehydroxylated kaolinite and $2 M 1$ muscovite in the XRD of the calcined phyllite based geopolymer resins show that both of these phases underwent alkaline activation, forming the amorphous geopolymeric phase.

It is possible that the dehydroxylazed muscovite $2 M 1$ content plays a limited role in the geopolimerization and consequently on its mechanical properties. The higher initial content of this mineral in WP could explain the highest performance for a phyllite-based geopolymer in this work (i.e. $25 \%$ WPG-6 resin).

XRD does not indicate differences in the structure of the geopolymers with $100 \%$ WPG calcined with different

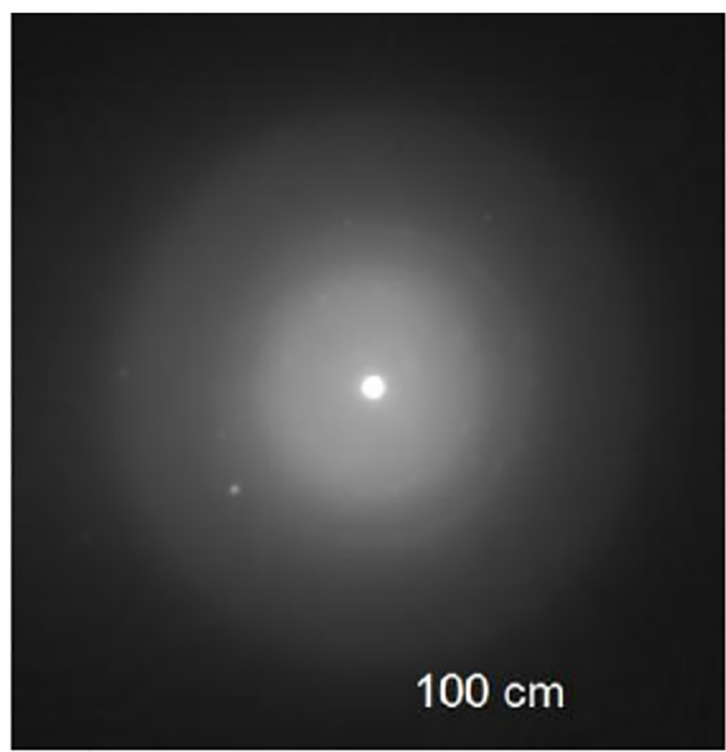

(b)

Figure 5. (a) TEM bright field image of the metakaolin-based geopolymer resin (SG) and (b) electron diffraction showing evidence of crystallinity. 


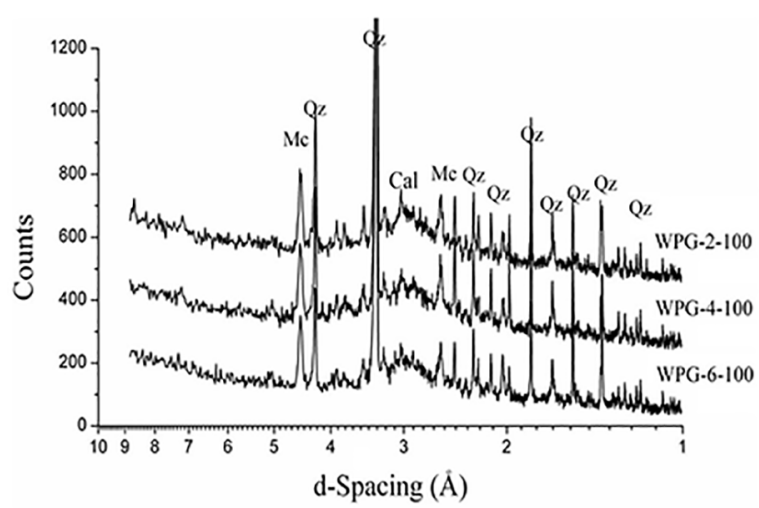

(a)

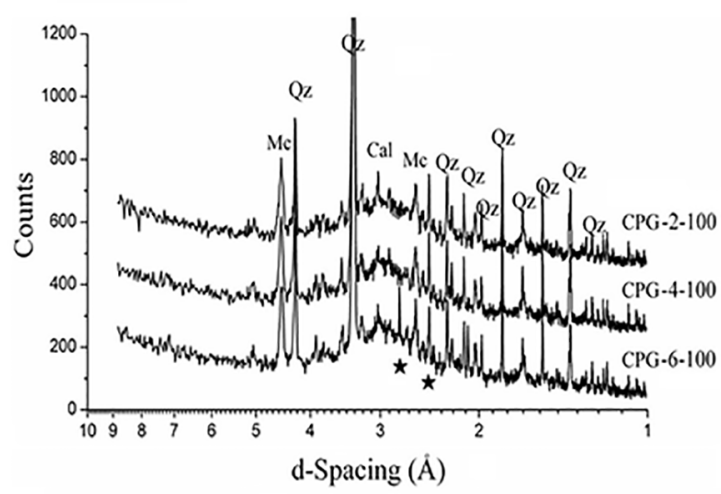

(b)

Figure 7. XRD of synthesized geopolymer resins evaluating the calcination time of the phyllites white (a) and cream (b), where indicates formation of new crystalline phase in the unidentified CPG-6-100.

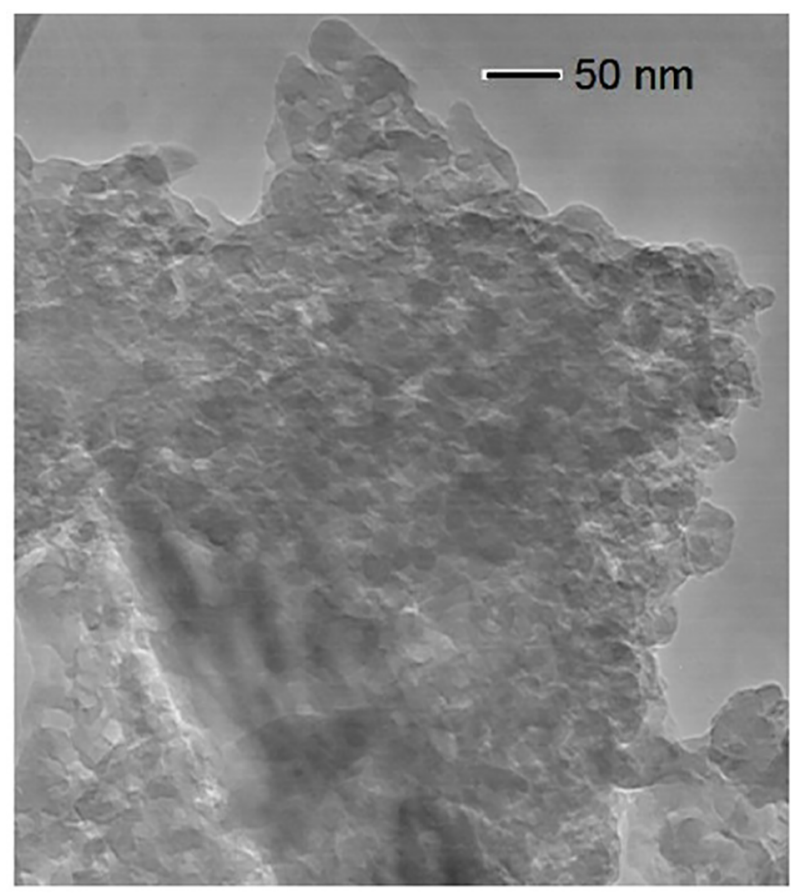

(a)

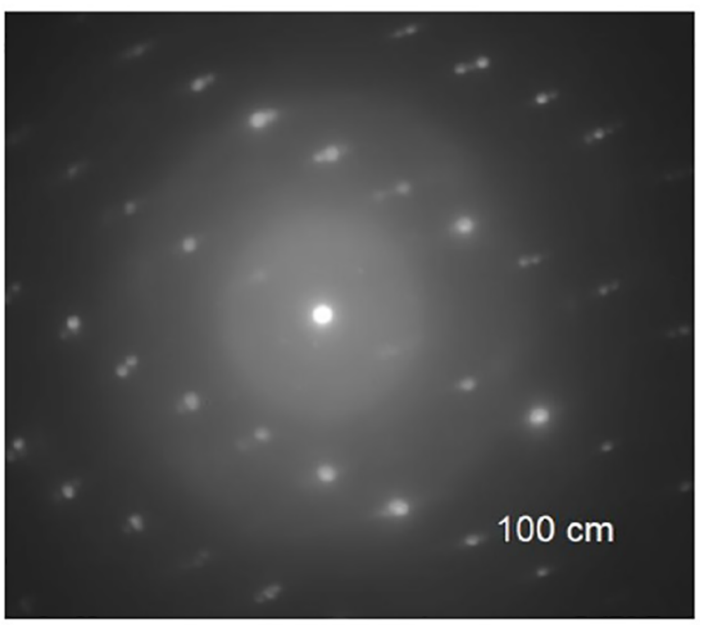

(b)

Figure 8. (a) Transmission electron micrograph of WPG-6-50, showing nanoparticles and revealing in (b) that they are crystalline and are embedded in an amorphous (geopolymeric) matrix.

times (Figure 7a). However, a new crystalline phase was observed in the CPG-6-100, which remains unindentified.

The nanoparticulate nature observed in the geopolymer resins with $100 \%$ metakaolin was also observed in those with $50 \%$ white phyllite, calcined for $6 \mathrm{~h}$ (WPG-6-50), as shown in Figure 8a. The electron diffraction pattern (Figure 8b) indicates that the analyzed region consists of an amorphous matrix, due to the diffuse rings, with crystalline particles oriented parallel to the optical axis, due to the small traces around the diffraction spots. The rows of spots may indicate superlattice, and the tiny distance between them depicts a large unit cell ${ }^{15}$.
It was not possible to identify the crystalline phase, but it is probably related to inert minerals present in the phyllite. This means that Figure 8a shows the gel phase (geopolymeric), impregnated with crystalline particles.

Increasing calcined phyllite content in the geopolymer resins resulted in increased unreacted raw materials and decreased amorphous material, as shown by XRD in the diffractograms shown in Figures 9a and 9b.

Both phyllite contain approximately only $40 \%$ of possible reactive mineral phases (muscovite $2 M 1$ and kaolinite) and $50 \%$ quartz (Table 3). However, not all of the muscovite is dehydroxylazed and will not be susceptible to the alkaline 


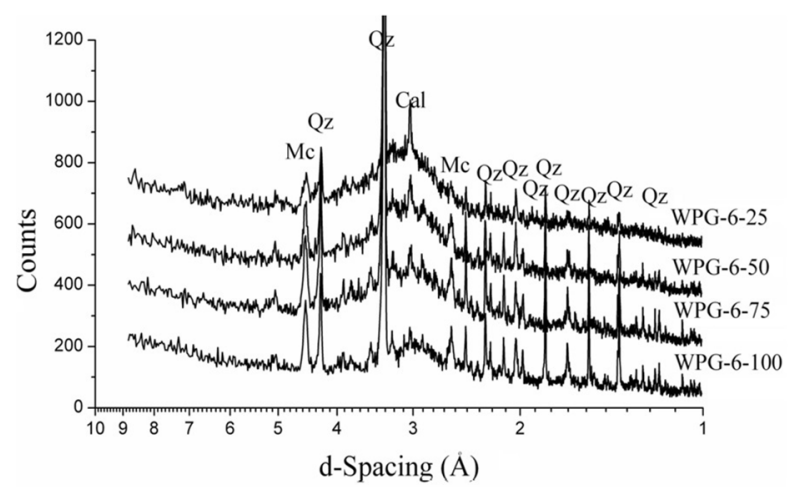

(a)

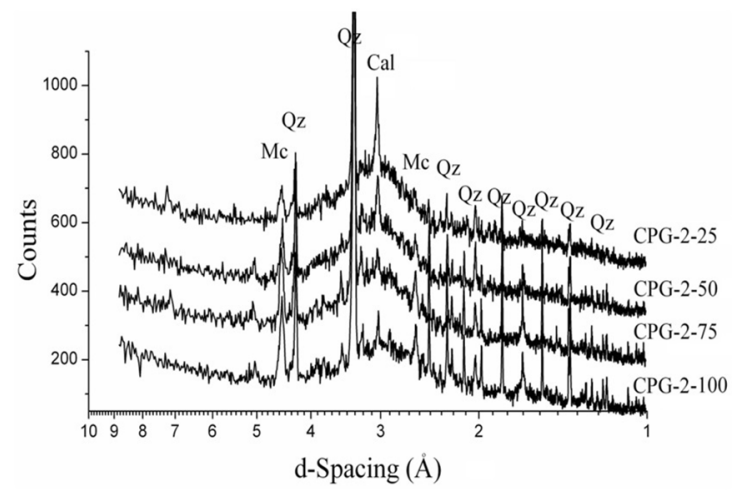

(b)

Figure 9. X-ray diffraction pattern of geopolymers with (a) 25, 50, 75 and $100 \% \mathrm{WP}-6$, (b) 25, 50, 75 and $100 \% \mathrm{CP}-2$, where Mc is $1 \mathrm{M}$ muscovite with PDF no 021-0993, Qz is quartz 046-1045 and Cal is calcite 005-0586.

attack. This doesn't mean muscovite doesn't play a role in the improvement of the compressive strength of the geopolymer. Uniformly dispersed nanosheets of layered silicate materials can facilitate transfer of stress from a polymer matrix to a reinforcement phase ${ }^{16}$. Although inert, the remaining minerals (i.e. quartz) can act as filler within the gel phase and, because it is an ultrafine particulate, it contributes to the compressive strength of the resin ${ }^{12}$. However, if the filler phase is present in larger amounts than the reactive phase as is the case for the $100 \%$ phyllite geopolymers, then the resulting resin is fragile as shown in Figure 4.

\section{Conclusions}

The mineralogical composition of the phyllite used to substitute metakaolin in the geopolymer resin plays a crucial role in its performance. The substitution of metakaolin with phyllite up to $50 \%$ in volume can improve the compressive strength of the geopolymer resin. Calcination of the phyllites resulted in dehydroxylation of both the kaolinite and muscovite $2 M 1$. Both of these phases react in the alkaline medium and contribute to the formation of the gel phase since they were not detected with XRD in the geopolymer resins. Crystalline quartz and muscovite remained in the calcined phyllites and in the geopolymer resins, indicating that these minerals do not participate in the geopolymerization. Although inert, quartz can act as a filler within the gel phase, because it is an ultrafine particulate, contributing to the increase in the compressive strength of the resins while muscovite can facilitate the stress transfer from the gel phase to the filler phase. Thus, it is confirmed that only the amorphous part of these reagents present reactivity under alkaline conditions, acting as a geopolymer precursor and substitute for metakaolin.

\section{Acknowledgements}

The authors thank Dr. Andre Pinto and the Multiuser Laboratories of Nanotechnology and Nanosciences (Lab-
NANO) and the X-ray Crystallography and Diffraction Center of the Centro Brasileiro de Pesquisas Físicas (CBPF) for the help and expertise with TEM analysis and XRD analyzes, respectively, the Laboratory of Analysis of Minerals and Rocks of the Universidade Federal do Paraná (UFPR) for the XRF analysis, FAPERJ for the financial support and the reviewers for their suggestions that improved the quality of this paper.

\section{References}

1. Vargas AS, Dal Molin DCC, Vilela ACF, Silva FJ, Pavão B, Veit $\mathrm{H}$. The effects of $\mathrm{Na}_{2} \mathrm{O} / \mathrm{SiO}_{2}$ molar ratio, curing temperature and age on compressive strength, morphology and microstructure of alkali-activated fly ash-based geopolymers. Cement \& Concrete Composites. 2011;33(6):653-660.

2. Davidovits J. Geopolymers: Inorganic Polymeric New Materials. Journal of Thermal Analysis. 1991;37:1633-1656.

3. Provis JL, Bernal SA. Geopolymers and Related AlkaliActivated Materials. Annual Review of Materials Research. 2014;44:299-327.

4. Catauro M, Papale F, Lamanna G, Bollino F. Geopolymer/PEG Hybrid Materials Synthesis and Investigation of the Polymer Influence on Microstructure and Mechanical Behavior. Materials Research. 2015;18(4):698-705.

5. Nazari A, Khalaj G. Prediction total specific pore volume of geopolymers produced from waste ashes by fuzzy logi. Materials Research. 2012;15(2):242-252.

6. Valera TS, Ribeiro AP, Valenzuela-Díaz FR, Yoshiga A, Ormanji $\mathrm{W}$, Toffoli SM. The effect of phyllite as a filler for PVC plastisols. In: Annual Technical Conference (Antec 2002); 2002 May 5-9; San Francisco, CA, USA.

7. Moreto ALR. Análises químicas e físicas do filito branco da região de Itapeva-SP visando o seu potencial de exploração. [Dissertation]. Curitiba: Universidade Federal do Paraná; 2004.

8. Garzón E, Sánchez-Soto PJ, Romero C. Physical and geotechnical properties of clay phyllites. Applied Clay Science. 2010;48(3):307-318. 
9. Barbosa VFF, Mackenzie KJD, Thaumaturgo C. Synthesis and characterization of materials based on inorganic polymers of alumina and silica: sodium polysialate polymers. International Journal of Inorganic Materials. 2000;2(4):309-317.

10. Zuhua Z, Xiao Y, Huajun Z, Yue C. Role of water in the synthesis of calcined kaolin-based geopolymer. Applied Clay Science. 2009;43(2):218-223.

11. Tailby J, Mackenzie KJD. Structure and mechanical properties of aluminosilicate geopolymer composites with Portland cement and its constituent minerals. Cement and Concrete Research. 2010;40(5):787-794.

12. Yousefi E, Majidi B. Effects of free quartz on mechanical behaviour of kaolinite based geopolymers. Materials Technology. 2011;26(2):96-99.
13. Obonyo EA, Kamseu E, Lemougna PN, Tchamba AB, Melo UC, Leonelli C. A Sustainable Approach for the Geopolymerization of Natural Iron-Rich Aluminosilicate Materials. Sustainability. 2014;6(9):5535-5553.

14. Lemougna PN, MacKenzie KJD, Jameson GNL, Rahier H, Chinje Melo UF. The role of iron in the formation of inorganic polymers (geopolymers) from volcanic ash: $\mathrm{A}^{57} \mathrm{Fe}$ Mössbauer spectroscopy study. Journal of Materials Science. 2013;48(15):5280-5286.

15. Williams DB, Carter CB. Transmission Electron Microscopy. A Textbook for Materials Science. New York: Springer; 2009. $779 \mathrm{p}$.

16. Hussain F, Hojjati M, Okamoto M, Gorga RE. Review article: Polymer-matrix Nanocomposites, Processing, Manufacturing and Application: An overview. Journal of Composite Materials. 2006;40(17):1511-1575. 